\title{
Abandonment processes at Middle Bronze Age Erimi: a multi-scalar approach
}

\author{
Marialucia Amadio ${ }^{1} \&$ Luca Bombardieri ${ }^{1, *}$
}

The study of abandonment processes is key to analysing the formation of social identities and the way that these identities are reinforced and maintained through social practices and rituals. Here, preliminary data from Middle Bronze Age Erimi, Cyprus, shed light on abandonment dynamics.

Keywords: Cyprus, Erimi, Bronze Age, micromorphology

\section{Introduction}

The study of abandonment processes in the archaeological record is key to reconstructing the life-history of buildings and settlements and the biographies of individuals, households and communities associated with them (Cameron 1993: 3-7). Abandonment processes reflect cultural responses to sociocultural, technological and environmental circumstances. Consequently, it is essential to contextualise abandonment practices within a sociocultural framework in order to examine and interpret the factors that generated and affected the formation of the archaeological record (Schiffer 1987).

At Middle Bronze Age Erimi-Laonin tou Porakou in Cyprus, abandonment sequences are examined by applying a multi-scalar analytical framework, based on the integration of macroanalysis of structures and artefacts and high-resolution micromorphological and Fourier transform infrared spectroscopy (FTIR) analyses of deposits and micro-materials. The aim is to generate richly networked data to study the spatial and temporal components of abandonment processes at Erimi at the end of the Cypriot Middle Bronze Age.

\section{Characterising Middle Bronze Age Erimi}

Analyses conducted by the University of Torino have revealed that the settlement was organised into distinct functional areas. On the top of the hill was the workshop complex (area A), which was principally designed for textile production; on the first sloping terraces, the domestic units (area B); a massive wall structure that limits the settlement to the west; and area Ean extramural cemetery on the lower southern terraces (Figure 1). Ongoing Bayesian radiocarbon dating and ceramic analysis confirm that the site was intensively occupied for approximately 300 years, in Middle Bronze Age Cyprus (1950-1650 BC) (Bombardieri 2017).

1 Erimi Archaeological Project, Università di Torino, Dipartimento Studi Umanistici, 20 Via S. Ottavio, 10124 Torino, Italy

* Author for correspondence (Email: luca.bombardieri@unito.it)

(C) Antiquity Publications Ltd, 2019

ANTIQUITY 93 368, e9 (2019): 1-7

https://doi.org/10.15184/aqy.2019.29 

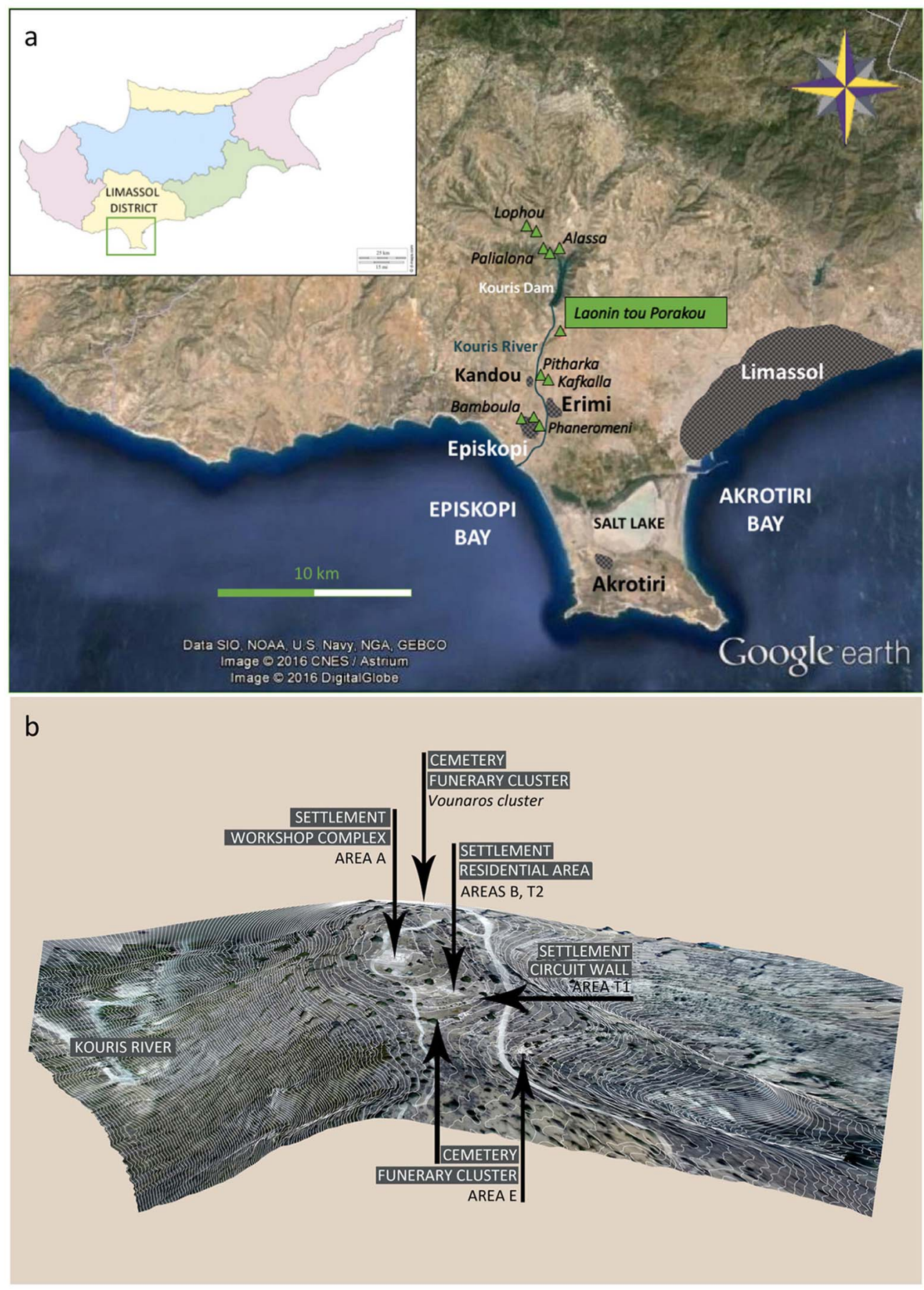

Figure 1. a) The site location; b) the topography of the settlement and funerary areas.

(C) Antiquity Publications Ltd, 2019 


\section{Reconstructing abandonment processes}

The study of abandonment sequences revealed the occurrence of two distinct abandonment dynamics:

\section{Gradual structural degradation}

This is characterised by the collapse of internal wall plaster, followed by the erosion of mudbrick walls and roofing structures, and by the collapse of stone wall bases (Figure 2a). This
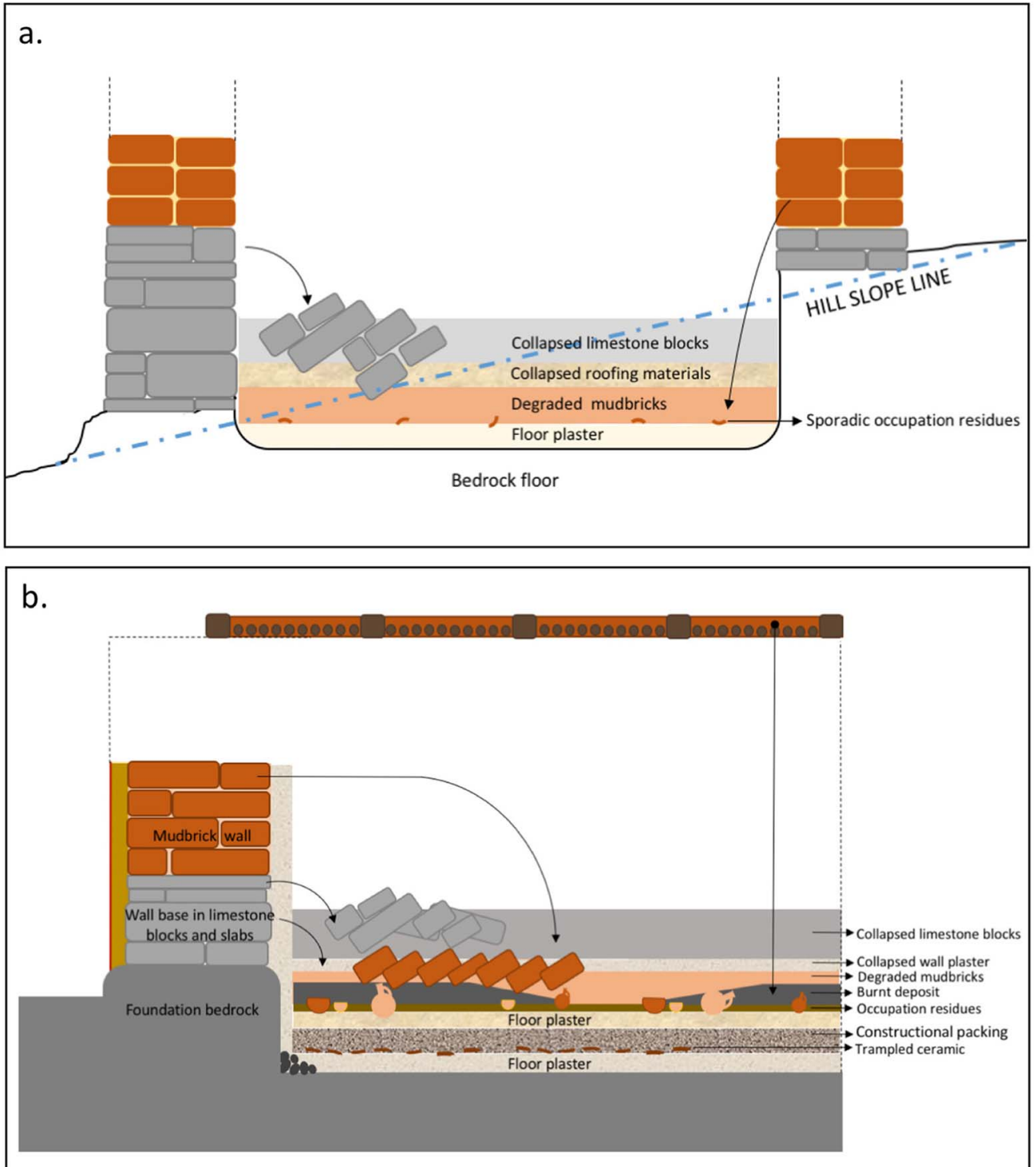

Figure 2. Graphs representing a) gradual degradation; b) the rapid destruction of buildings.

(C) Antiquity Publications Ltd, 2019 


\section{Area A - WORKSHOP COMPLEX}

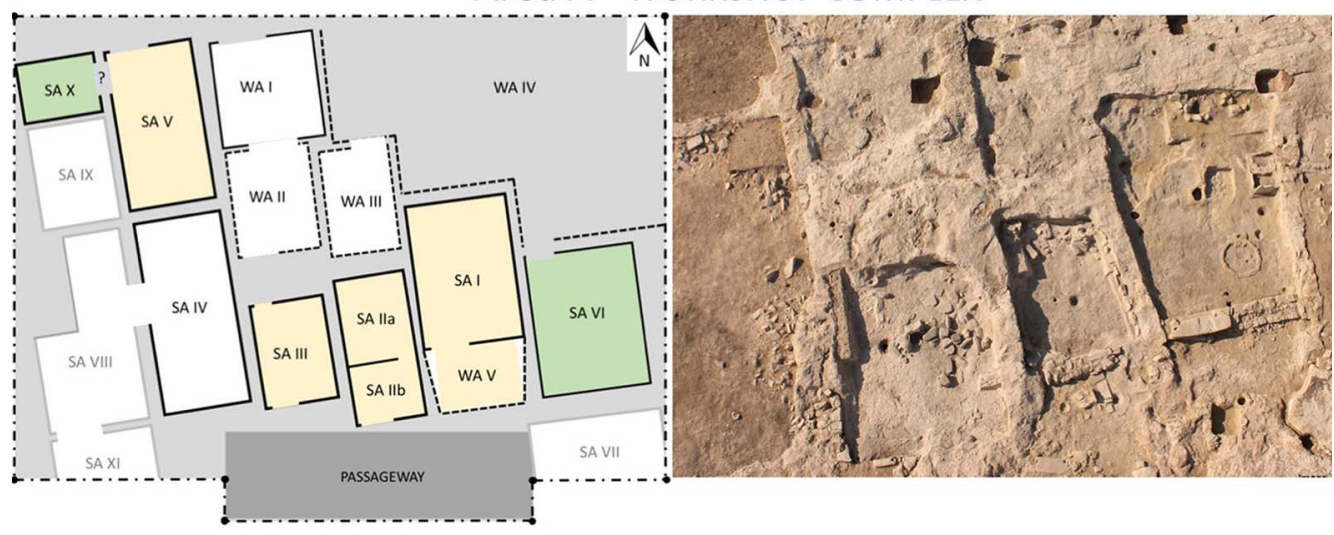

\section{Area B - DOMESTIC QUARTER}
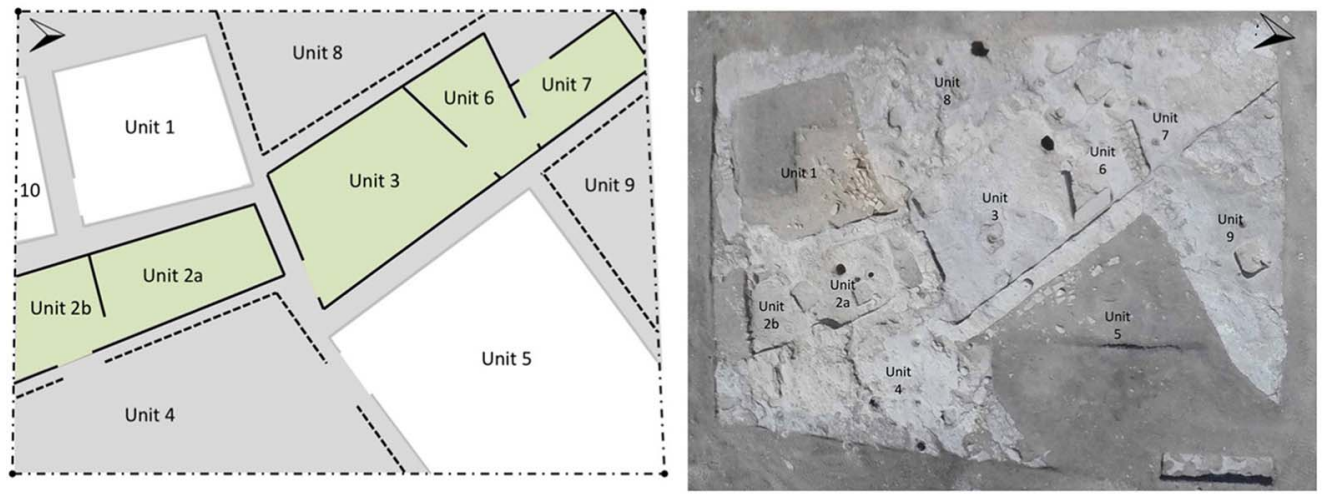

GRADUAL DEGRADATION

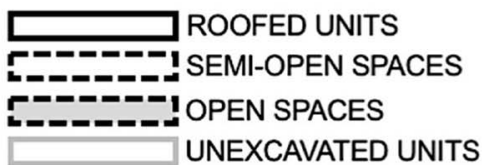

FAST DESTRUCTION UNEXCAVATED UNITS

Figure 3. Identified abandonment processes.

natural degradation process is attested principally in buildings in the residential area (Figure 3), where slow burial of the structures affected the preservation of the underlying occupation deposits. Micromorphological analysis revealed the occurrence of disturbance by roots and faunal activity in occupation deposits. Stratigraphic analysis indicates the almost complete absence of vessels and tools on the occupation floors.

\section{Fast destruction}

This is caused by a fire event that completely sealed the occupation surfaces and deposits and preserved intact installations, artefacts and micro remains. This process is exclusively (C) Antiquity Publications Ltd, 2019 


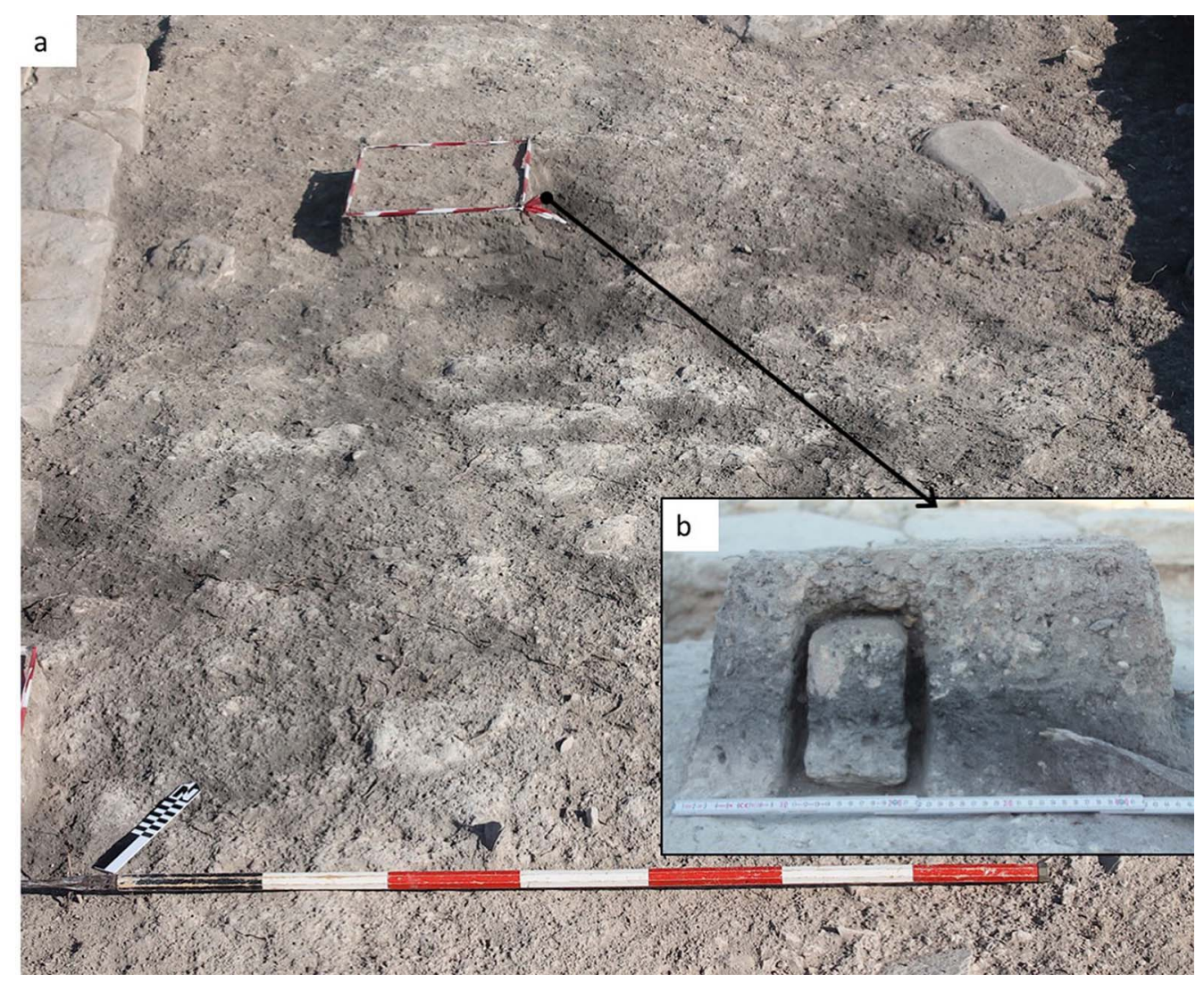

Figure 4. Workshop complex. Unit SA V: a) burnt and mud-brick layers; b) section showing the sequence of burnt layer covered by degraded mud-bricks.

attested in communal buildings of the workshop complex (Figure 3). Here, stratigraphic and microstratigraphic analyses revealed the occurrence of layers of burnt sediments and lenses of hardened sediments, which have been interpreted as possible ignition points (Harrison 2004). These burnt layers are covered by the collapse of mud-brick walls (Figures $2 \mathrm{~b} \& 4$ ), which are preserved intact due to the hardening process caused by fire. Micromorphological and FTIR analyses of mud-bricks show further evidence for vitrification and oxidation, as well as anomalies in the clay peaks of spectra recorded-these may derive from structural changes caused by prolonged exposure to high temperatures (Berna et al. 2007).

\section{Identifying sociocultural practices: arson or accidental fire?}

It is difficult to confirm if the fire event recorded in the workshop complex was deliberate or accidental. The idea of a possible arson may be suggested by comparative experimental analysis and examination of the archaeological evidence:

(C) Antiquity Publications Ltd, 2019 


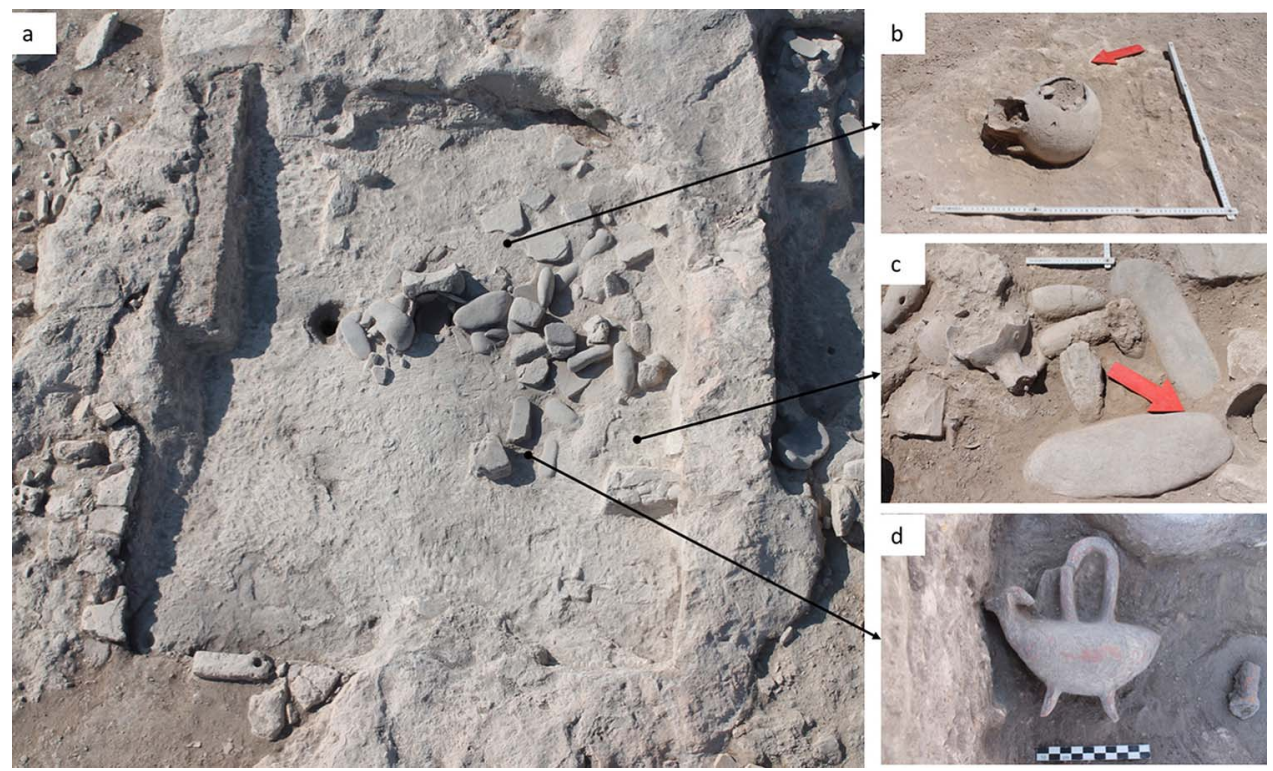

Figure 5. Workshop complex. Unit SA III: a) layer of stones intentionally deposited on the occupation surface; $b-d)$ intact vessels and tools recovered from the occupation surface.
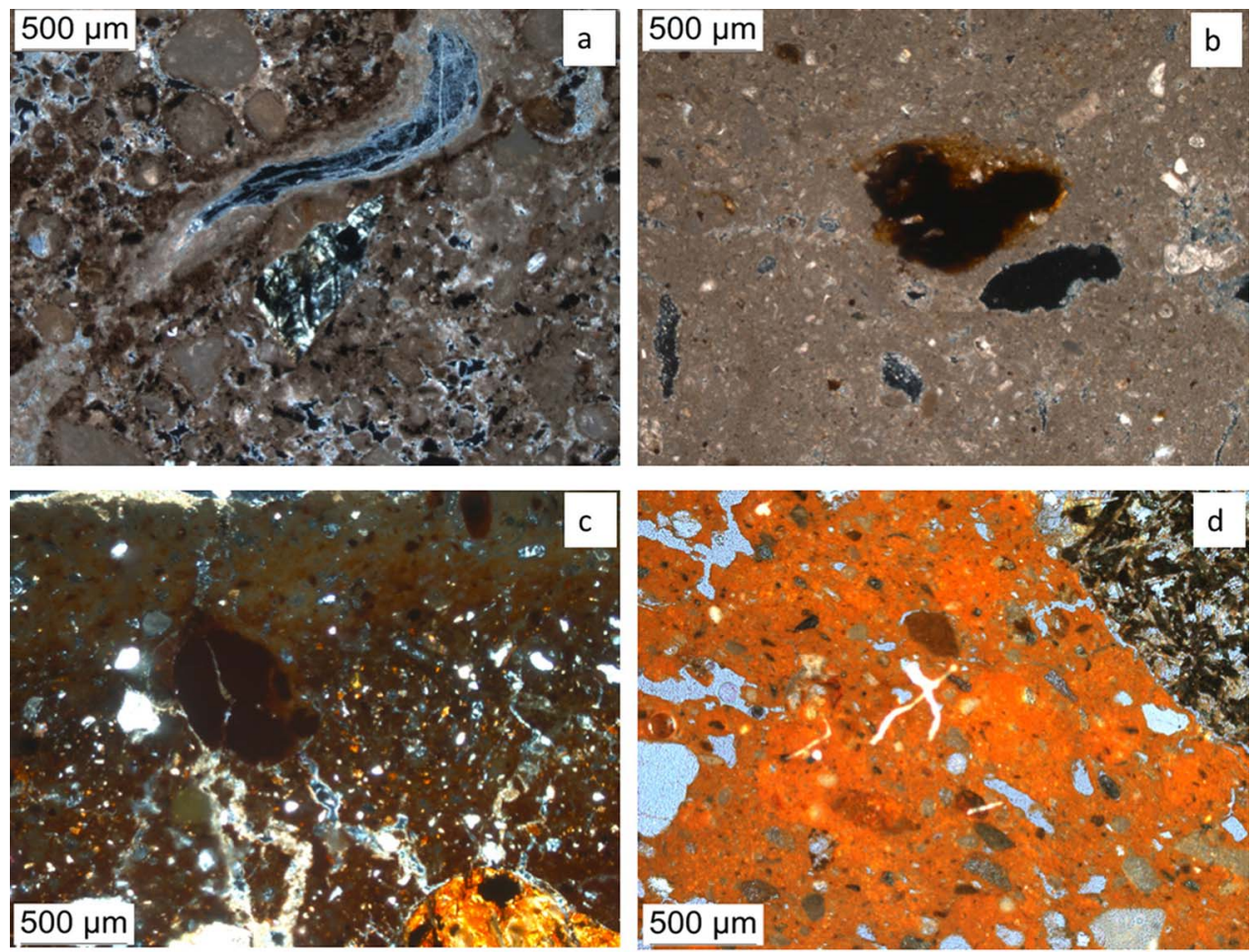

Figure 6. Photomicrographs showing: a) bioturbated deposits with burrows and reworking - area B; b) oxidation; c) vitrification; d) reddening identified in mud-brick layers — area A.

(C) Antiquity Publications Ltd, 2019 
1. Experimental analysis and forensic fire investigations demonstrated that mud-brick structures are difficult to ignite without accelerants and additional fuel (Harrison 2004).

2. Stratigraphic analysis revealed the occurrence of intact vessels on the latest occupation floor of many buildings. The presumed deliberate placement of these objects within buildings may be considered part of a commemorative and ritual practice conducted before the abandonment.

Unit SA III is an interesting example of deliberate abandonment. Here, a layer of re-used rubber stones and sterile sediment was intentionally deposited to seal the latest occupation level, which included intact vessels and working tools (Figures 5-6). Based on this evidence, we support the idea of the intentional burning of buildings as part of an organised effort of 'sealing off; this act was possibly intended to create an enduring symbolic continuation of community identity in that place (Stevanovic 1997).

\section{Conclusions}

The Erimi evidence suggests that, in residential contexts, when houses were left, personal objects were removed by their owners; in communal buildings of the workshop complex, most of the structures were presumably burnt, and selected objects were left behind as part of collective memories.

\section{References}

Berna, F., A. Behar, R. Shahack-Gross, J. Berg, E. Boaretto, A. Gilboa, I. Sharon, S. Shalev, S. Shilstein, N. Yahalom-Mack, J.R. Zorn \& S. WeIner. 2007. Sediments exposed to high temperatures: reconstructing pyrotechnological processes in Late Bronze and Iron Age Strata at Tel Dor (Israel). Journal of Archaeological Science 34: 358-73. https://doi.org/10.1016/j.jas.2006.05.011

Bombardieri, L. 2017. Erimi Laonin tou Porakou. A Middle Bronze Age community in Cyprus. Excavations 2009-2014. Uppsala: Åström Förlag.

Cameron, C.M. 1993. Abandonment and archaeological interpretation, in C.M. Cameron \& S.A. Tomka (ed.) Abandonment of settlements and regions. Ethnoarchaeological and archaeological approaches: 3-7. Cambridge: Cambridge University Press.

Harrison, K. 2004. Fire and burning at Çatalhöyük. Integrating forensic practice. Çatalhöyük Archive Report 2004. Available at: http://www.catalhoyuk.com:8080/ archive_reports/2004 (accessed 14 February 2019).

Schiffer, M.B. 1987. Formation processes of the archaeological record. Albuquerque: University of Mexico Press.

Stevanovic, M. 1997. The age of clay: the social dynamics of house destruction. Journal of Anthropological Archaeology 16: 334-95. https://doi.org/10.1006/jaar.1997.0310

Received: 3 November 2018; Accepted: 27 November 2018; Revised: 31 January 2019

(C) Antiquity Publications Ltd, 2019 